University of Nebraska - Lincoln

DigitalCommons@University of Nebraska - Lincoln

Immunogenicity and protective efficacy of the Mycobacterium avium subsp. paratuberculosis attenuated mutants against challenge in a mouse model

Jenn-Wei Chen

Syed M. Faisal

Subhash Chandra

Sean P. McDonough

Maria A.S. Moreira

See next page for additional authors

Follow this and additional works at: https://digitalcommons.unl.edu/usdaarsfacpub

Part of the Agriculture Commons

This Article is brought to you for free and open access by the U.S. Department of Agriculture: Agricultural Research Service, Lincoln, Nebraska at DigitalCommons@University of Nebraska - Lincoln. It has been accepted for inclusion in Publications from USDA-ARS / UNL Faculty by an authorized administrator of DigitalCommons@University of Nebraska - Lincoln. 


\section{Authors}

Jenn-Wei Chen, Syed M. Faisal, Subhash Chandra, Sean P. McDonough, Maria A.S. Moreira, Joy Scaria, Chao-Fu Chang, J. P. Bannantine, Bruce Akey, and Yung-Fu Chang 


\title{
Immunogenicity and protective efficacy of the Mycobacterium avium subsp. paratuberculosis attenuated mutants against challenge in a mouse model
}

\author{
Jenn-Wei Chen ${ }^{a}$, Syed M. Faisal ${ }^{a}$, Subhash Chandra ${ }^{a}$, Sean P. McDonough ${ }^{b}$, Maria A.S. Moreira ${ }^{a}$, \\ Joy Scaria ${ }^{\mathrm{a}}$, Chao-Fu Chang ${ }^{\mathrm{c}}$, John P. Bannantine ${ }^{\mathrm{d}}$, Bruce Akey ${ }^{\mathrm{a}}$, Yung-Fu Chang ${ }^{\mathrm{a}, *}$ \\ a Animal Health Diagnostic Center, Department of Population Medicine and Diagnostic Sciences, College of Veterinary Medicine, Cornell University, Ithaca, NY 14853, USA \\ b Biomedical Sciences, College of Veterinary Medicine, Cornell University, Ithaca, NY 14853, USA \\ c Institute of Medical Biotechnology, Central Taiwan University of Science and Technology, Taichung, Taiwan \\ ${ }^{\mathrm{d}}$ National Animal disease Center, USDA-ARS, Ames, IA, USA
}

\section{A R T I C L E I N F O}

\section{Article history:}

Received 10 September 2011

Received in revised form 7 November 2011

Accepted 8 November 2011

Available online 19 November 2011

\section{Keywords:}

Mycobacterium avium subsp.

paratuberculosis

Mutant

Johne's disease

leuD, mpt64

secA2

\begin{abstract}
A B S T R A C T
Johne's disease (JD), caused by Mycobacterium avium subsp. paratuberculosis (MAP), results in serious economic losses worldwide especially in cattle, sheep and goats. To control the impact of JD on the animal industry, an effective vaccine with minimal adverse effects is urgently required. In order to develop an effective vaccine, we used allelic exchange to construct three mutant MAP strains, leuD, mpt64 and secA2. The mutants were attenuated in a murine model and induced cytokine responses in J774A.1 cell. The leuD mutant was the most obviously attenuated of the three constructed mutant strains. Our preliminary vaccine trial in mice demonstrated different levels of protection were induced by these mutants based on the acid-fast bacilli burden in livers and spleens at 8 and 12 weeks postchallenge. In addition, vaccination with leuD mutant induced a high level of IFN- $\gamma$ production and significant protective efficacy in both the reduction of inflammation and clearance of acid-fast bacilli, as compared with the mock vaccinated group.
\end{abstract}

(c) 2011 Elsevier Ltd. All rights reserved.

\section{Introduction}

The hallmark of Johne's disease (JD), caused by Mycobacterium avium subsp. paratubculosis (MAP) infection in ruminants, is chronic granulomatous enteritis that leads to diarrhea and, eventually, death [1-3]. JD is highly prevalent not only in the United States, but also worldwide. The estimated annual loss caused by JD for the dairy industry in the United States alone is more than \$220 million [4,5]. Calves are infected by ingesting MAP shed in the feces of cattle that are in the preclinical or clinical phase of the disease. The elimination of MAP bacteria from the environment is very difficult and thus, an effective vaccine would be extremely beneficial in the control of JD in herds.

The currently available JD vaccine for animal use consists of killed MAP bacteria in an oil suspension. Although the killed bacteria elicit protective immunity in animals against MAP infection, protection is incomplete and varies widely depending on vaccination protocols. The recent availability of an annotated whole genomic sequence of the MAP K-10 strain has led to

\footnotetext{
* Corresponding author. Tel.: +1 607253 3675; fax: +1 6072533943

E-mail address: yc42@cornell.edu (Y.-F. Chang).
}

significant advances in knowledge of MAP gene regulation in bacterial metabolism [6]. Comparative genomic approaches with MAP and Mycobacterium tuberculosis (MTB) have also led to the identification of homologous genes involved in pathogenesis and conserved metabolic pathways.

We previously reported the results of MAP subunit vaccine trials in mice, goats, and calves [7-11]. Unfortunately, the cost of expression and purification of recombinant proteins and adjuvants necessary to manufacture subunit vaccines precludes their use in food animals. Therefore, we conducted further studies aimed at identifying efficacious yet cost effective vaccines in order to provide herd managers additional tools to control JD. Several attempts have been made to develop attenuated mutants as live vaccine candidates for JD [12,13]. In the present study, we constructed three MAP mutant strains, leuD, mpt64, and secA2 using wild type MAP K10 . The leuD gene encodes isopropylmalate isomerase, an enzyme involved in leucine biosynthesis. The auxotroph leuD mutant of Mycobacterium bovis-derived bacillus Calmette Guérin (BCG) is unable to grow in macrophages and is cleared within 7 weeks from the lungs and spleen $[14,15]$. Although the leuD mutant does not provide better protection than BCG, it still induces immunity against MTB bacteria in BALB/c mice [16]. In addition, the $M$. bovis leuD mutant induces highly significant protective immunity against a virulent $M$. bovis strain in cattle [17]. Because the MAP bacterium 
is closely related to the MTB bacterium, it is reasonable to hypothesize that the MAP leuD mutant would also provide protective immunity against MAP infection.

The mpt64 gene encodes the immunogenic secreted protein mpt64, which is involved in apoptosis of multinucleated giant cells (MGCs) $[18,19]$. Expression of mpt64 in MTB granulomas is negatively correlated to apoptosis; hence Mpt64 may play a role in the persistence of Mycobacterium infected macrophages and mpt64 mutants may be defective and unable to escape from host immune responses $[18,19]$. The secA2 gene encodes one small component of the Sec-dependent protein secretion pathway in Mycobacterium. Studies of MTB secA2 deletion mutants indicate SecA2 is required for the secretion of some anti-oxidation proteins such as SodA and KatG $[20,21]$. Further, the MTB secA2 mutant is attenuated in SCID mice [20], and enhances apoptosis of infected macrophages [21]. Vaccination of mice and guinea pigs with an MTB secA2 mutant significantly increases resistance to MTB challenge compared with BCG vaccination [21]. Hence, the secA2 MAP mutant is another potential vaccine candidate against MAP infection.

In this report, we describe the pathogenicity and protective efficacy of three MAP deletion mutants in C57BL/6 mice. The results showed that all three mutants were removed effectively from the liver and spleen whereas unvaccinated control mice could not remove the MAP K-10 strain effectively. Moreover, all mutants were able to induce protective immunity when vaccinated mice were challenged with a virulent MAP strain. Among the three mutant strains, leuD was associated with lower lesion severity, and mycobacteria were eliminated more effectively. In addition, the leuD mutant also induced higher IFN- $\gamma$ levels and provided better protective immunity against MAP infection.

\section{Materials and methods}

\subsection{Bacterial strains and culture methods}

Liquid cultures of MAP K-10 strain (ATCC, Manassas, VA), and MAP clinical isolate strain 66115-98 were grown in Middlebrook 7H9 broth (BD, Sparks, MD) supplemented with $0.24 \%$ glycerol, $0.05 \%$ Tween $80,1.2 \mathrm{mg} / \mathrm{ml}$ casitone (BD), $1.25 \mathrm{mg} / \mathrm{l}$ mycobactin J (Allied Monitor, Inc., Fayette, MO), and 10\% Middlebrook OADC Enrichment (BD). Solid cultures were grown on 7H10 agar supplemented as described above. leuD, mpt64, and secA2 mutants were cultured on 7H9 broth with $75 \mu \mathrm{g} / \mathrm{ml}$ hygromycin B (HygB). All broth cultures were grown at $37^{\circ} \mathrm{C}$ in T75 tissue culture flasks. Before challenge, the optical density of the bacterial cultures was checked and the bacterial cells were harvested by centrifugation at $1500 \times g$ for $10 \mathrm{~min}$. After washing with the same volume of PBS, the cells were resuspended in an appropriate volume of PBS buffer.

\subsection{Plasmid construction, allelic replacement}

The three deletion strains were constructed as previously described [22-24]. The primers used to construct the allelic exchange substrate (AES) of leuD, mpt64, and secA2 genes are shown in Table 1 . The primer pairs were designed using the MAP K-10 genome sequence database to amplify the upstream and downstream fragments from K-10 genomic DNA. After digesting with appropriate enzymes, both fragments were cloned into pYUB854 on either side of the HygB resistance $\left(\mathrm{Hyg}^{\mathrm{r}}\right)$ cassette to generate the AES [25]. The pYUB854 plasmid containing the AES was digested with PacI and ligated with plasmid phAE87. The resulting plasmid was packaged with in vitro $\lambda$-packaging extract (Gigapack III-XL; Stratagene), and incubated with E coli HB101 on a low-salt LB agar plate containing $100 \mu \mathrm{g} / \mathrm{ml}$ of HygB. The pooled phAE87-AES plasmid DNA was prepared from Hyg $^{\mathrm{r}}$ colonies and electroporated into
Table 1

Primers used in this study.

\begin{tabular}{ll}
\hline Primer & Sequence \\
\hline leuD 5' flanking forward & CTGAGATCTTCAAGACGATGGCGGTCAACGTCGAC \\
leuD 5' flanking reverse & CTACTCGAGCTCATCCCTTCACGGTCGAATACGTC \\
leuD 3' flanking forward & GACTCTAGAAGCGACGTATCCCGATTGGAAACCG \\
leuD 3' flanking reverse & GTCGGTACCAGGACGTGCTCTGCCTACTTGCGG \\
mpt64 5' flanking forward & CTGAGATCTCCACCGACCCGGCGGTTCGCAGGAC \\
mpt64 5' flanking reverse & CTACTCGAGGCGCATGTTGGATCCCTCCCGAGG \\
mpt64 3' flanking forward & GACTCTAGAAGGTGAGTGGGTGCCCGATGTGGTGG \\
mpt64 3' flanking reverse & GTCGGTACCGACTGGCCGAACTTCTCGCCCAGACC \\
secA2 5' flanking forward & CTGAGATCTCGCCGACATCCGCTGGCCTCTCC \\
secA2 5' flanking reverse & CTACTCGAGCACAGGTCAACGGTACCGGTGGGGCG \\
secA2 3' flanking forward & GACTCTAGACGCTAGCCGGTGCGCGGCCAGCCGCG \\
secA2 3' flanking reverse & GTCGGTACCCGCCGGGCGTAGCCGGGATCCAGATG \\
leuD 5' checking & TGCTGGCCACCCAGACGTTGCCGC \\
leuD 3' checking & GCCGGCCGAAGGGTATTCGTGTC \\
mpt64 5' checking & CCAAGCTGGCCAACAACGCGATC \\
secA2 5' checking & AACTGGCCATCCCGGTGCTGATG \\
il12b RT forward primer & ACCCTGCCCATTGAACTG \\
il12b $R T$ reverse primer & CTTCAAAGGCTTCATCTGCAAG \\
\hline
\end{tabular}

Mycobacterium smegmatis $\mathrm{mc}^{2} 155$ to generate the phage particle. After incubation at the permissive temperature $\left(30^{\circ} \mathrm{C}\right)$ for 3 days, several plaques were picked up for amplification on a 7H10 plate. The high-titer transducing mycobacteriophages were prepared by washing the amplified plaques with MP buffer ( $50 \mathrm{mM}$ Tris- $\mathrm{HCl} \mathrm{pH}$ 7.6, $150 \mathrm{mM} \mathrm{NaCl}, 10 \mathrm{mM} \mathrm{MgSO}_{4}, 2 \mathrm{mM} \mathrm{CaCl}_{2}$ ).

MAP K-10 was cultured in $40 \mathrm{ml}$ of $7 \mathrm{H} 9$ broth medium in a T75 tissue culture flask until the OD600 was 0.6-0.8. The culture was removed to a $50-\mathrm{ml}$ tube and allowed to stand for $10 \mathrm{~min}$ to deposit large clumps of bacteria by gravity. Thirty-five milliliters of the top layer of the culture was then removed into a new 50-ml tube and centrifuged at $1500 \times g$ for $10 \mathrm{~min}$. The bacterial pellet was resuspended in an equal volume of MP buffer and centrifuged again to remove residual Tween 80 . The pellet was resuspended carefully in $1 / 10$ of the original volume in MP buffer. Equal volumes of hightiter mycobacteriophage stock and bacterial cells were mixed in a 2 -ml screw cap tube and incubated at $37^{\circ} \mathrm{C}$ for $4-6 \mathrm{~h}$. The mixture was added to $2 \mathrm{ml}$ of $7 \mathrm{H} 9$ broth medium containing casitone (BD), cultured at $37^{\circ} \mathrm{C}$ for an additional $48 \mathrm{~h}$ for recovery, and the cells were then harvested by centrifugation at $2000 \times \mathrm{g}$ for $10 \mathrm{~min}$. The pellet was resuspended with $1 \mathrm{ml} 7 \mathrm{H} 9$ medium and each $200 \mu \mathrm{l}$ of the resuspended cultures was then plated on 7H10 medium with $75 \mu \mathrm{g} / \mathrm{ml} \mathrm{HygB}$. After 6 weeks of incubation, 20 colonies were selected for analysis; the genomic DNA of colonies containing the Hyg resistance cassette was prepared for PCR reaction and DNA sequencing in order to confirm allelic exchange.

\subsection{Mice}

Female C57BL/6 mice 6-8 weeks old were purchased from Taconic (Germantown, NY). The animals were housed in a biosafety level II facility with free access to feed and water. All of the experimental work was conducted in compliance with the regulations, policies, and principles of the Animal Welfare Act, the Public Health Service Policy on Humane Care and Use of Laboratory Animals used in Testing, Research, and Training, the NIH Guide for the Care and Use of Laboratory Animals and the New York State Department of Public Health.

\subsection{Cell line culture, infection, RNA purification, and $q R T-P C R$ of IL6, IL12b and IL10}

J774A.1 murine macrophage cell line was purchased from ATCC. The cells were routinely grown in DMEM supplemented with $10 \%$ FBS, penicillin-G (100 units/ml), and streptomycin sulfate $(100 \mathrm{mg} / \mathrm{ml})$. J774A.1 cells grown in 24-well tissue culture plates 
were infected with mycobacterial strains, at a 30:1 multiplicity of infection (MOI). After $4 \mathrm{~h}$, the infection was terminated by washing cells two times with PBS to remove extracellular mycobacteria. The cells were grown in DMEM supplemented with $10 \%$ FBS, Gentamicin $(50 \mu \mathrm{g} / \mathrm{ml})$ for an additional $48 \mathrm{~h}$. After treating with $5 \times$ volume of RNAprotect Cell Reagent (Qiagen), three wells of cells with the same treatment were pooled together for preparation of total RNA using RNeasy Plus Mini Kit (Qiagen). High quality RNA (RNA integrity value RIN > 6.0) was used for cDNA synthesis using SuperScript III kit (Invitrogen). Real-time PCR was performed with 7500 Fast System and SyberGreen PCR Master Mix (Applied Biosystems, Foster City, CA) to determine transcript expression of Interleukin-6 (IL6), Interleukin-12b (IL12b) and Interleukin-10 (IL10); the gapdh transcript levels were used as the internal control of $2^{-\Delta \Delta C_{\mathrm{T}}}$ method. The primers used in real-time PCR were purchased from Qiagen (il6: PPM03015A, il10: PPM03017B and gapdh: PPM02946E) and from Integrated DNA Technologies (Coralville, Iowa). The melting curve analysis of the PCR products was performed to verify their specificity and identity.

\subsection{Pathogenicity, immunization, and challenge studies}

Thirty-two mice were used to study pathogenicity of the MAP mutant strains; the mice were divided into 4 groups: group K-10 was inoculated with $5 \times 10^{8} \mathrm{CFU}$ of MAP K-10 strain intraperitoneally while the other three groups (leuD, mpt64, and secA2) were inoculated with the same number of mutant bacteria in the same way. Four mice from each group were sacrificed at 8 and 12 weeks after inoculation. The liver and spleen were collected aseptically for determination of the bacterial load and histopathological changes. A total of 128 mice (16 mice/group) were used to determine the protective efficacy of MAP mutant strains in two independent experiments; mock vaccinated mice were given PBS buffer intraperitoneally while group leuD, mpt64, and secA2 were vaccinated with $1 \times 10^{7} \mathrm{CFU}$ of the respective mutant strain intraperitoneally. Three weeks after vaccination, all groups were given a booster dose as described above. Six weeks later, all the groups were challenged with $5 \times 10^{8} \mathrm{CFU}$ of MAP strain clinical isolate 66115-98 intraperitoneally. Eight mice from each group were sacrificed at 8 and 12 weeks after challenge, the liver and spleen were collected aseptically to determine bacterial load, histopathological changes, and the immune responses. The collected tissues were fixed by immersion in $10 \%$ neutral buffered formalin, embedded in paraffin wax, sectioned at $4 \mu \mathrm{m}$ and stained with hematoxylin and eosin and Ziehl-Neelson by conventional histological methods as previously described [26]. Tissue sections were examined by a board certified veterinary pathologist (SPM), who was blinded to the treatment groups.

\subsection{Preparation of spleen cells}

The mouse spleens were collected aseptically into a sterile $70 \mu \mathrm{m}$ cell strainer over a 6 -well cell culture plate half filled with RPMI 1640 media as previously described [7,10]. The spleens were subjected to mechanical disruption by gently pressing them through the cell strainer using a $5 \mathrm{ml}$ syringe plunger and flushing with sterile RPMI 1640 . The disaggregated cells were transferred to a fresh $50 \mathrm{ml}$ tube and centrifuged at $500 \times \mathrm{g}$ for $10 \mathrm{~min}$. The cell pellet was resuspended in ACK lysis solution ( $3 \mathrm{ml} \mathrm{ACK} \mathrm{lysis} \mathrm{solution}$ per spleen) at room temperature for 2 min to lyse red blood cells. Next, two volumes of RPMI 1640 medium was added to dilute the ACK lysis solution and the splencytes were pelleted by centrifugation at $500 \times \mathrm{g}$ for $10 \mathrm{~min}$ at RT. After being washed two times in an equal volume of RPMI 1640 medium, the cell pellet was resuspended with RPMI 1640 medium and the cell number was adjusted to $1 \times 10^{7}$ cells $/ \mathrm{ml}$. The average cell viability was greater than $95 \%$ as determined by trypan blue dye exclusion.

\subsection{Cytokine ELISA}

Spleen cells were cultured in duplicate in round bottom 96-well tissue culture plates with $1 \times 10^{6}$ cells/well for $24 \mathrm{~h}$. After stimulating with $10 \mu \mathrm{g} / \mathrm{ml}$ of MAP purified protein derivative (PPD) (NVSL, Ames, Iowa) for an additional $48 \mathrm{~h}$, IFN- $\gamma$ ELISA was performed using an ELISA kit according to the manufacture's instructions (eBioscience, CA). PPD had been checked for non-specific stimulation by using spleen cells from a mouse without any treatment.

\subsection{Flow cytometric analysis}

Spleen cells were cultured in duplicate in round bottom 96-well tissue culture plates with $1 \times 10^{6}$ cells/well for $24 \mathrm{~h}$. After stimulating with PPD from MAP for an additional $48 \mathrm{~h}$, FACS analysis was performed with standard procedures. Briefly, cells were washed three times with FACS buffer (1\% BSA and $0.05 \%$ sodium azide in PBS) and resuspended in $50 \mu$ l of FACS buffer with the same volume of PE conjugated antibodies (anti-CD4 or anti-CD8) diluted for optimum performance as determined by prior titration (eBioscience, San Diego, CA), and incubated on ice for $30 \mathrm{~min}$. Cells were washed twice with FACS buffer and suspended in $100 \mu \mathrm{l}$ of $3 \%$ formaldehyde in PBS and transferred to FACS tubes containing $300 \mu \mathrm{l}$ of PBS. Data were collected on 10,000 events using a FACS caliber flowcytometer (Becton-Dickinson, San Jose, CA) and analyzed using Cellquest software.

\subsection{Statistical analysis}

Microsoft Office Excel software was used to perform Student's $t$-test statistical analysis. Differences between groups were considered significant when a probability value of $<0.05$ was obtained.

\section{Results}

\subsection{Construction of deletion mutations in M. avium subsp. paratuberculosis}

To examine the degree of pathogenicity and protective efficacy of mutant genotypes of MAP (leuD, mpt64, and secA2), the targeted genes were disrupted by phage-mediated allelic exchange, which replaced the targeted genes with the hygromycin resistance gene cassette. As shown in Fig. 1A and B, PCR reaction of leuD, mpt64, and secA2 genes in the mutants yielded different PCR product sizes compared to those of wild type $\mathrm{K}-10$, confirming gene replacement. The region of the gene replacement in each mutant was also examined by DNA sequencing of the PCR product (data not shown). In addition, the growth curve of mutants in 7H9 broth was compared to that of wild type K-10 (Fig. 1C). The growth curve of leuD mutant was low while that of other two mutants was only slightly decreased compared to the growth curve of the K-10 strain.

\subsection{Pathogenicity of MAP mutants in C57BL/6 mice}

To determine if the constructed MAP mutants were attenuated, C57BL/6 mice were injected intraperitoneally with the mutant and wild type $\mathrm{K}-10$ strains and mice were sacrificed at 8 and 12 weeks. As shown in Fig. 2A and B, most mice showed different levels of inflammation in the liver and spleen at both time points. In the liver, the majority of the mice (3/4) infected with mpt64 had mild inflammation (level 1 ) at week 8 , and all mpt64-inoculated mice had inflammation under level 4 (severe level) at week 12. At both 


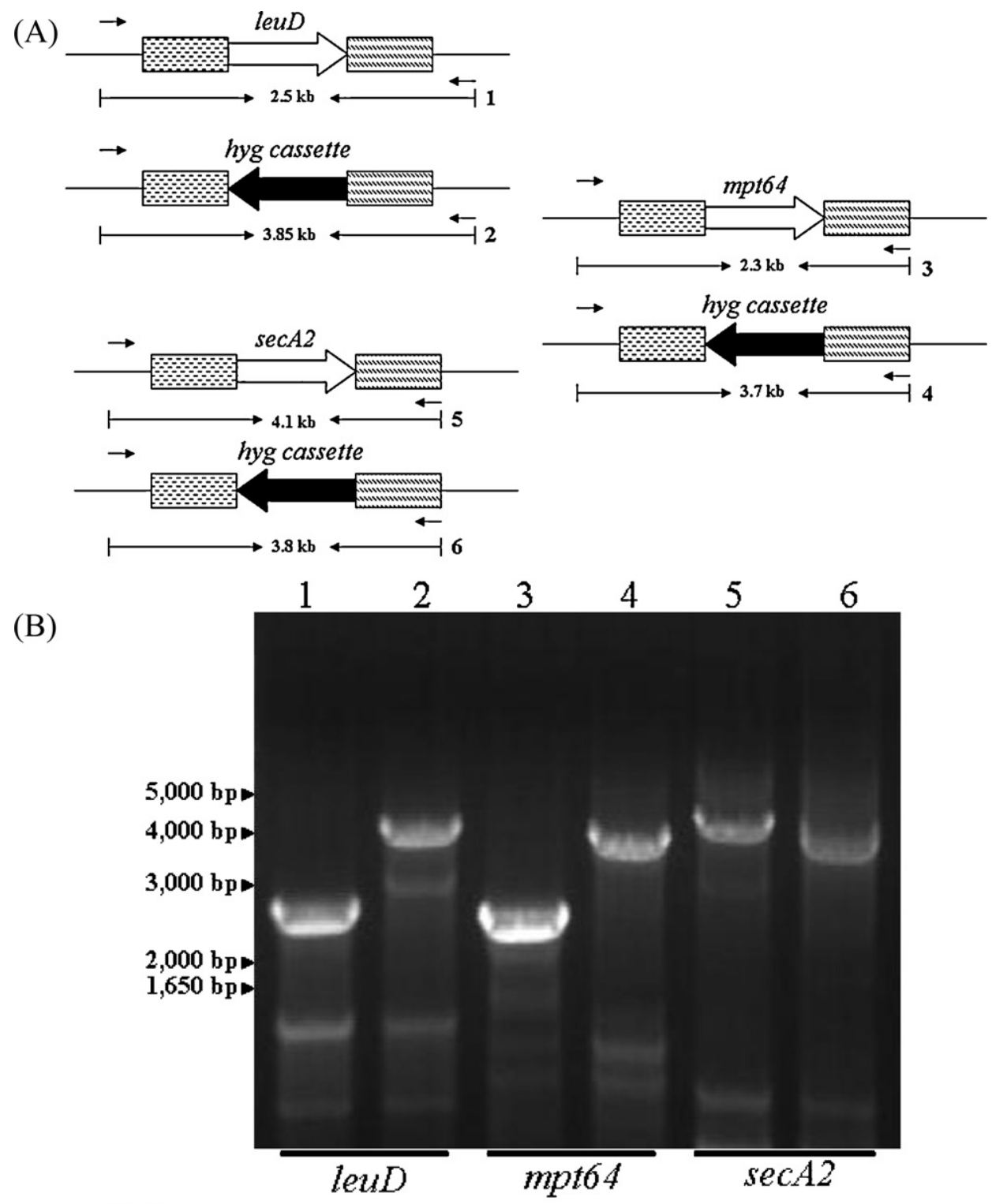

(C)

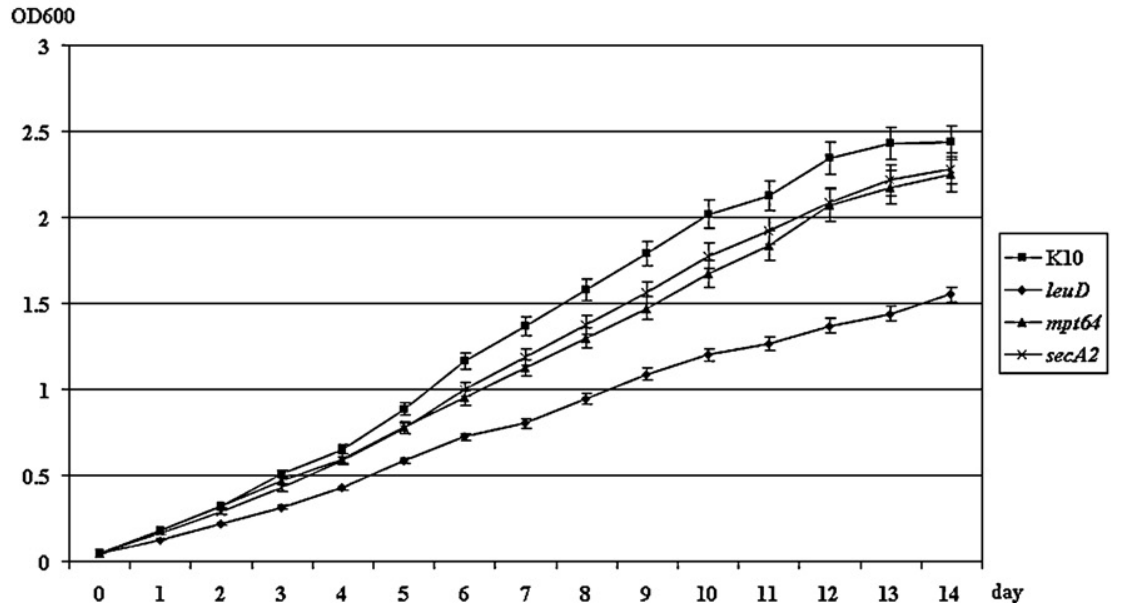

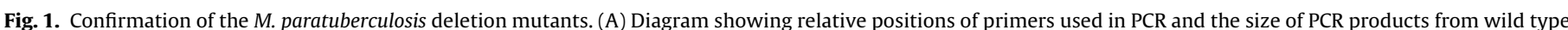

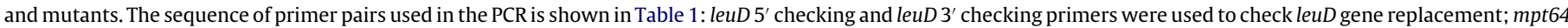

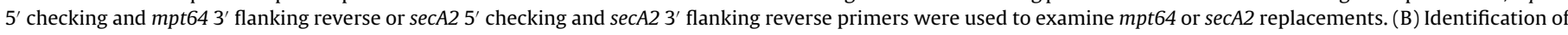

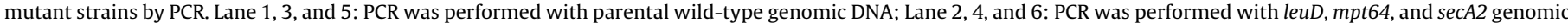
DNA. (C) The growth curve of mutant strains in 7H9 broth was determined and each strain was examined in triplicate. 

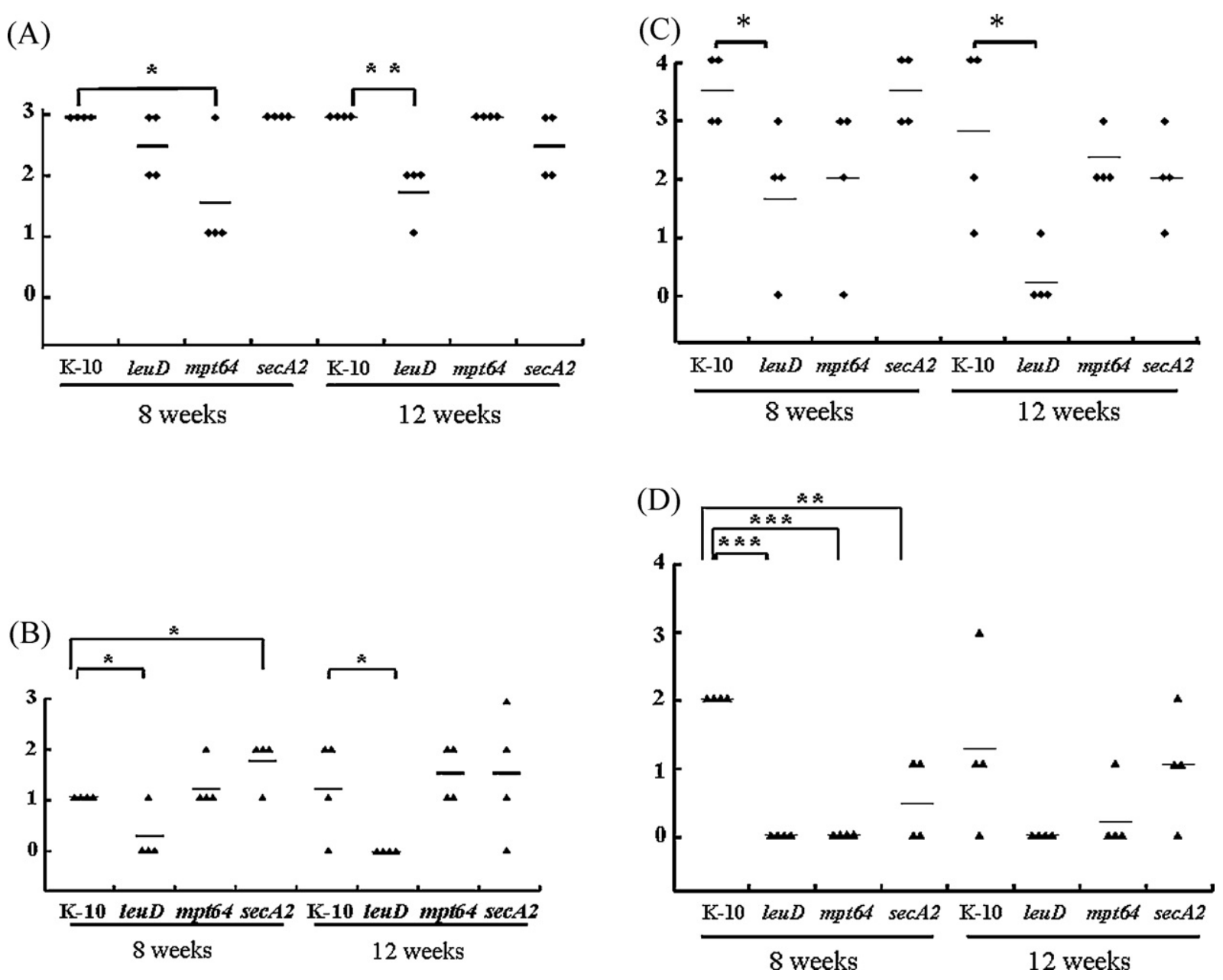

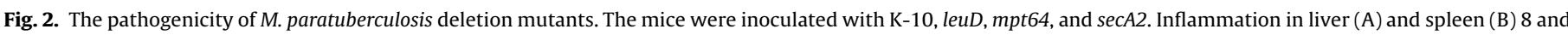

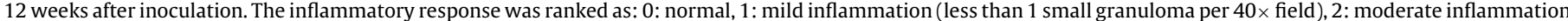

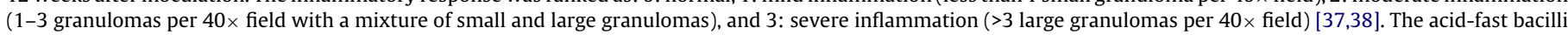

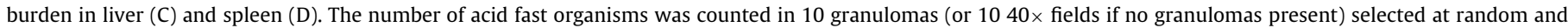
ranked as: 0: no visible acid fast organisms, 1: <1/granuloma, 2: 1-10/granuloma, 3: 11-25/granuloma, and 4: >25/granuloma.

time points, the leuD-inoculated mice $(7 / 8)$ had no inflammation in the spleen, which was significantly different compared to the K10 -inoculated mice. In addition, Ziehl-Neelsen staining was used to determinate the number of acid-fast bacilli in tissues (Fig. 2C and D). Compared with the wild type K-10-inoculated group, the leuDinoculated group showed significant differences at both time points in liver; and no acid-fast bacilli could be detected in the spleen at either time point. The mpt64- and secA2-inoculated groups had significantly fewer numbers of acid-fast bacilli than the K-10 group in the spleen at week 8; although both groups had a lower bacterial burden in liver than wild type group, this difference was not statistically significant. Based on the results (Fig. 2), the leuD mutant strain was the most attenuated.

\subsection{Cytokine IL6, IL10 and IL12b expression in MAP-infected J774A.1 cell}

In order to determine if significant pro- and anti-inflammatory cytokine gene expression changes are produced in macrophages infected with the MAP mutant strains, we quantified IL6, IL12b and IL10 expression levels in J774A.1 cells infected with the various MAP strains using the qRT-PCR method. The relative expression of the pro-inflammatory cytokines IL6 and IL12b was significantly decreased in J774A.1 cells infected with the mutant strains as compared to K-10 infection (Fig. 3A); among the three mutants, secA2 infection induced lower IL6 and IL12b level than other two mutants and K-10. Expression of the anti-inflammatory cytokine IL10 also changed in response to infection with the mutant strains (Fig. 3B); the IL10 level increased more than 4-fold and 10-fold in leuDand secA2-infected J774A.1 cells, respectively (compared to the K10-induced IL10 expression level). Conversely, unlike other two mutants, mpt64 infection induced J774A.1 cell to express lower IL 10 than wild-type $\mathrm{K}-10$ infection. In addition, leuD, the most attenuated strain in the pathogenicity studies, induced lower IL6 expression ( 0.6 fold) and higher IL10 expression ( 4 fold) than K-10.

\subsection{Protective effects of MAP mutants in C57BL/6 mice}

In order to evaluate MAP mutants' ability to elicit immunity, we carried out challenge experiments in a mouse model. At the beginning, the leuD mutant was used to determine the vaccine dosage that would induce the greatest protective effects. After vaccination with different bacterial numbers and challenge with virulent MAP 66115-98 clinical isolate strain, four mice were sacrificed from each group at 8 and 12 weeks after challenge. As shown in Fig. 4, the number of granulomas in the liver was lowest in the group vaccinated with $1 \times 10^{7}$ bacteria as compared to the other vaccinated groups. The MAP burden in the liver and spleen were examined in all of the vaccinated groups at week 12; in the vaccinated group given $1 \times 10^{7} \mathrm{CFU}$ and a booster, no MAP could be detected in splenic 

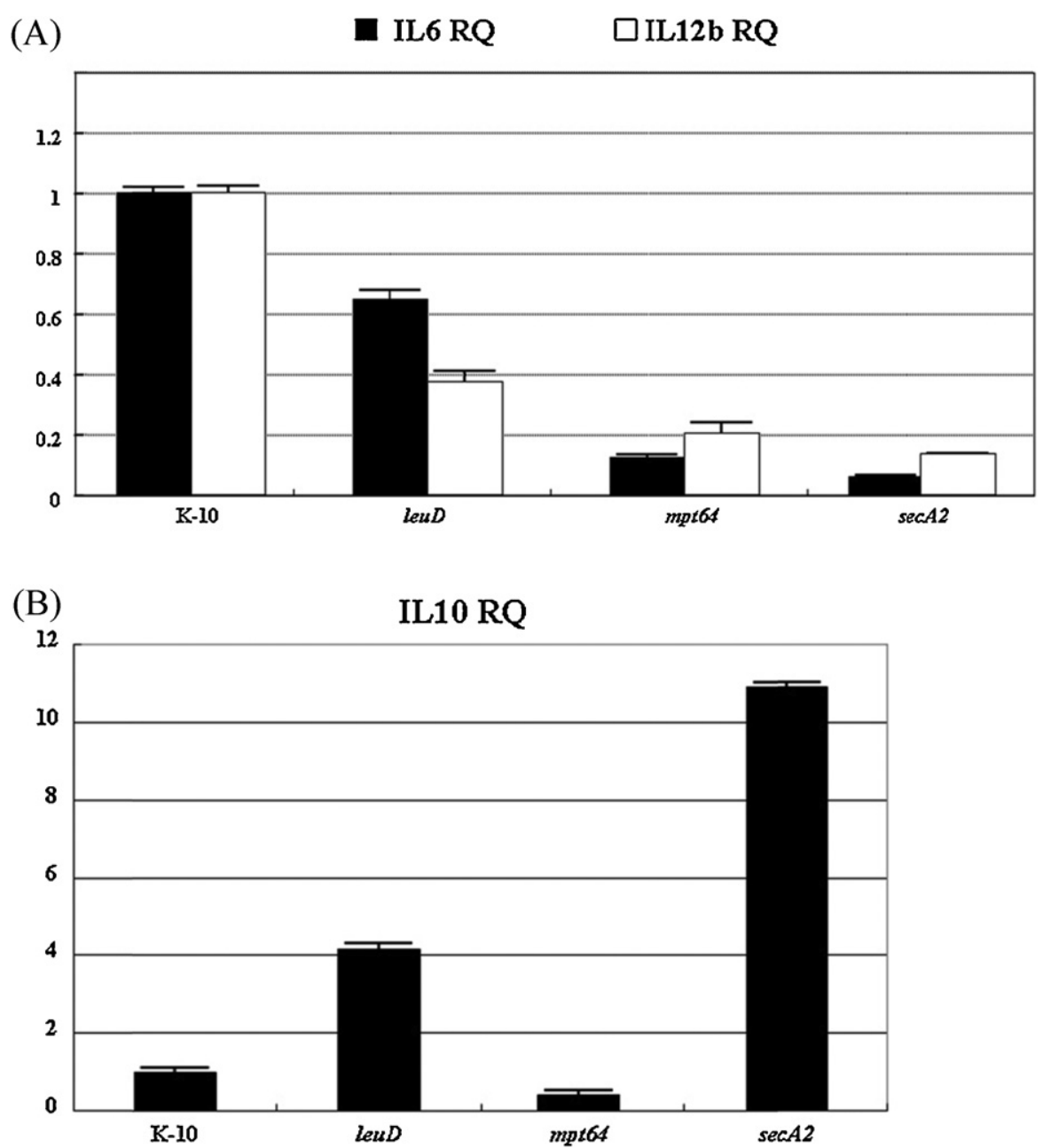

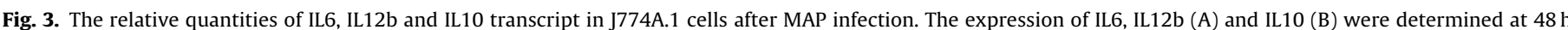

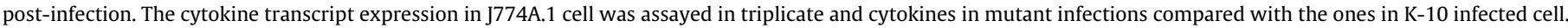
Height of the error bars indicates SD of the mean.

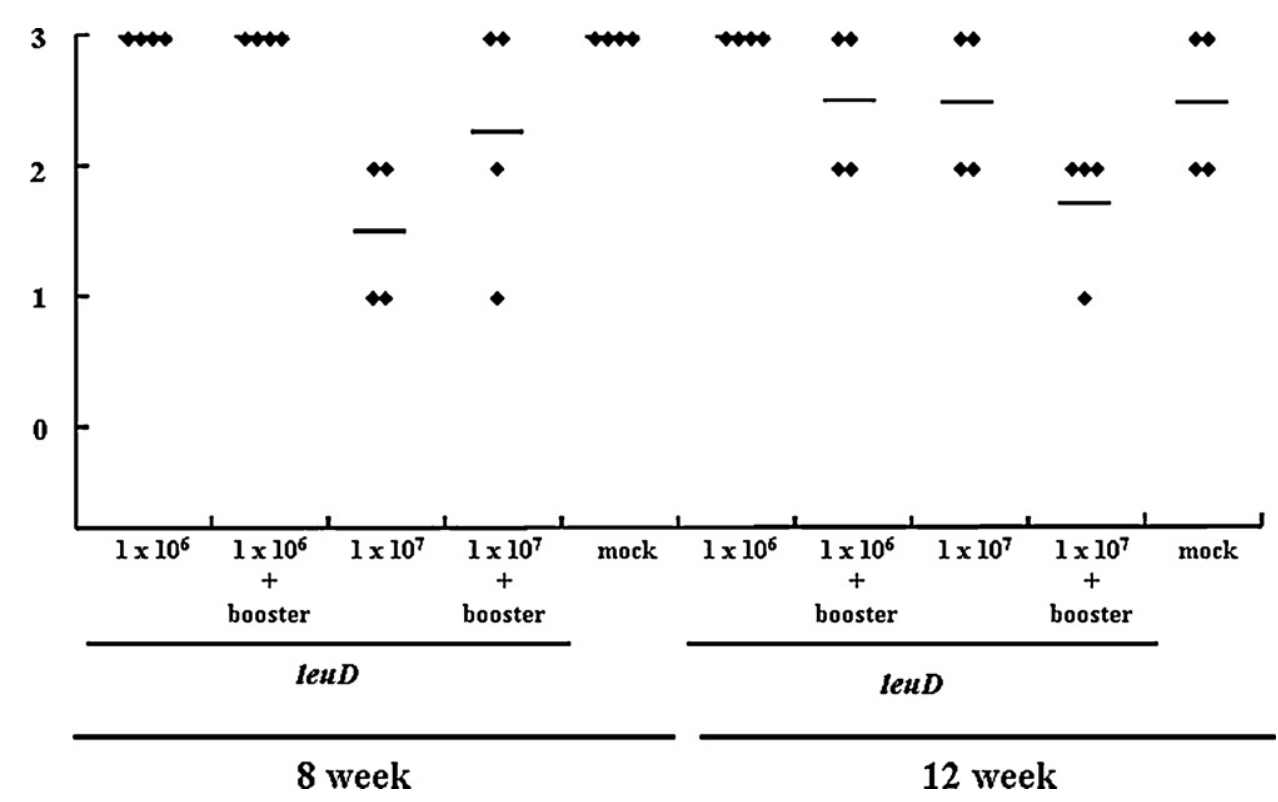

Fig. 4. The determination of optimum bacterial loading used in vaccination. The degree of inflammation in the liver was examined at 8 and 12 weeks after challenge. 
(A)

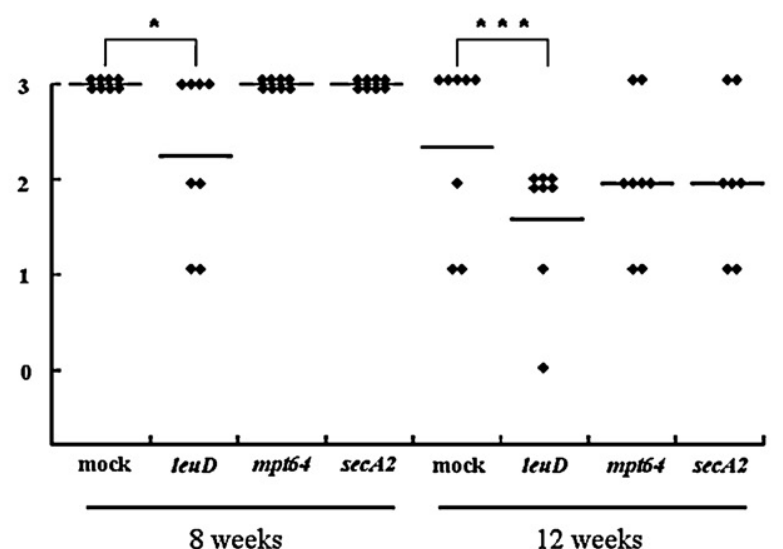

(B)

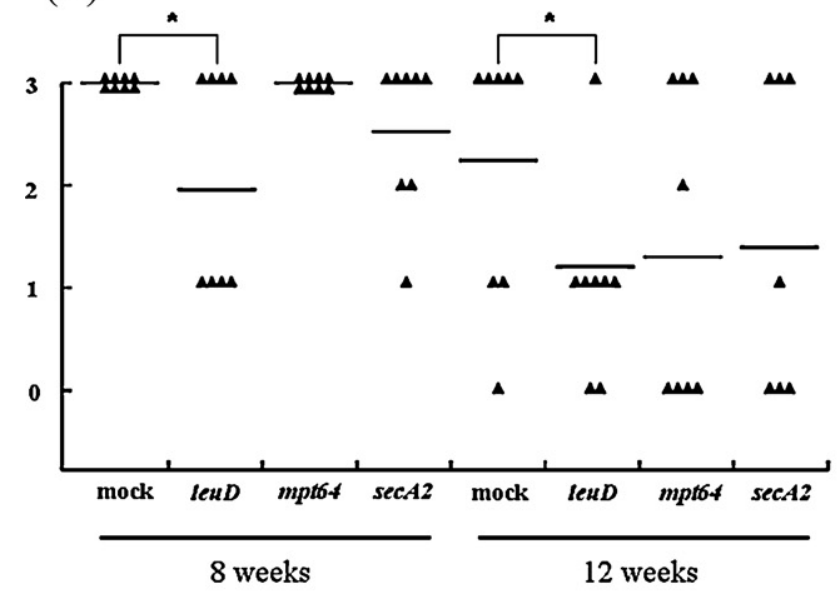

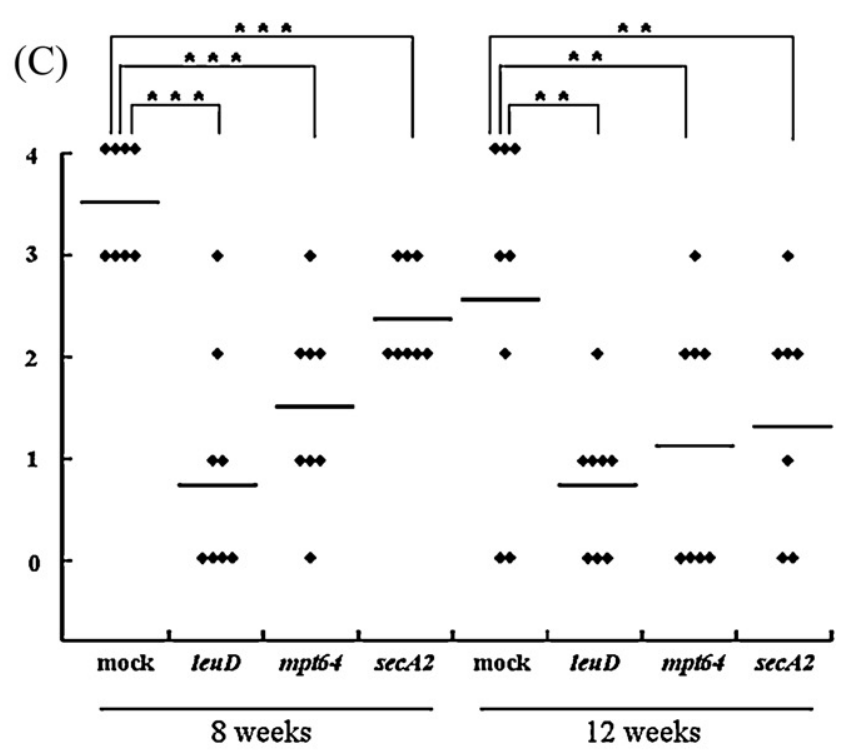

(D)

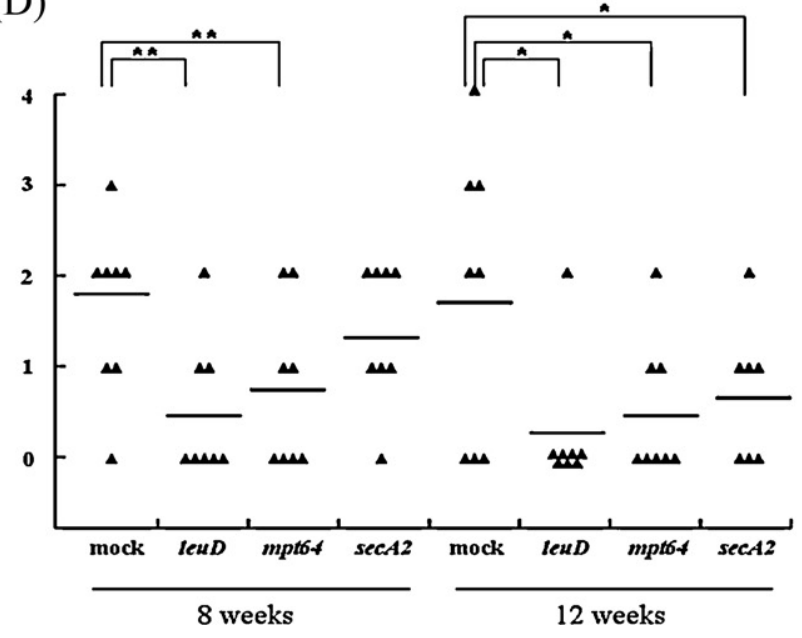

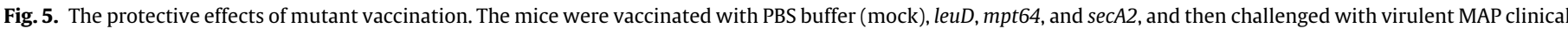

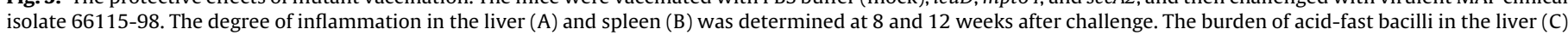
and spleen (D) was examined at the same time. The ranking is as described in Fig. 2.

tissues and approximately 9 colonies grew from $1 \mathrm{mg}$ of liver tissue; by comparison, the group given $1 \times 10^{6} \mathrm{CFU}$ and a booster, $4 \mathrm{CFU} / \mathrm{mg}$ and $15 \mathrm{CFU} / \mathrm{mg}$ were recovered from the spleen and liver, respectively. Thus, $1 \times 10^{7} \mathrm{CFU}$ of mutants with a single booster was used to vaccinate mice in the following vaccination trials. After vaccination with mutants and challenge with virulent MAP 66115-98 clinical isolate strain, eight mice were sacrificed from each group at 8 and 12 weeks. As shown in Figs. 5 and 6, the degree of inflammation among the groups was almost same at week 8 , but all of the mice in mock-vaccinated group had severe inflammation (level 3). leu $D$-Vaccinated group showed significantly reduced inflammation ( 2 mice in moderate degree and 2 mice in mild degree at week 8; 6 mice in moderate degree, 1 mouse in mild degree and 1 mouse in normal degree at week 12) in the liver as compared to the mockvaccinated group. mpt64- and secA2-vaccinated groups had slightly fewer granulomas as compared to the control group at week 12 but the differences were not statistically significant. At the same time, the number of acid-fast bacilli in tissue samples was also counted (Fig. 5C and D). The results showed that mutant-vaccinated groups had significantly lesser numbers of acid-fast bacilli compared to the control group, except the secA2-vaccinated group at week 8 . From week 8 to week 12, the number of acid-fast bacilli in all of the mutant-vaccinated groups trended downward, especially in the spleen.

Our data confirmed that vaccination with mutants resulted in fewer granulomas and lesser numbers of acid-fast bacilli in the liver and spleen compared to mock-vaccinated mice (Fig. 6). Among all mutants, the leuD-vaccinated group elicited greater protective efficacy than the others.

\subsection{Specific immunological responses of vaccination trial}

We also analyzed the expression of IFN- $\gamma$ induced by MAP PPD stimulation in isolated splenocytes from all vaccinated groups 8 and 12 weeks postchallenge. Although mock-vaccinated mice after challenge with MAP still expressed some specific IFN- $\gamma$ secretion under MAP PPD or rAgs treatment, all other groups showed higher expression levels of IFN- $\gamma$ secretion (Fig. 7A). At the same time, the PPD-specific CD4+ and CD8+ T cell proliferation of splenocytes from all vaccinated groups stimulated with PPD were determined through flow cytometric analysis (Fig. 7B and C). Compared to controls, all of the mutant-vaccinated groups had a higher PPDspecific CD4+ $T$ cell percentage at week 8 and week 12 . At week 8 , all of the mutant-vaccinated groups had a greater 
mock

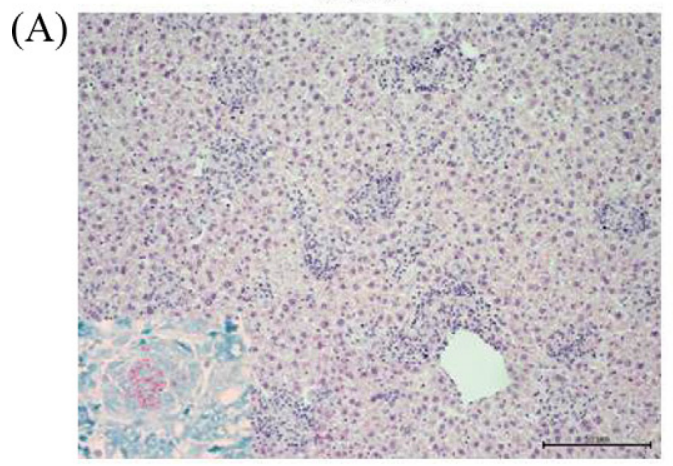

mpt64

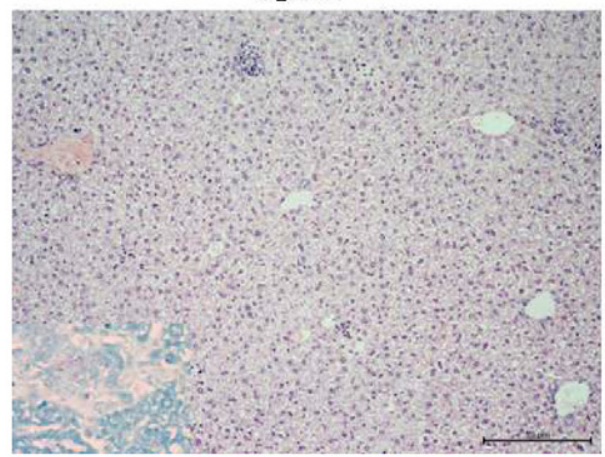

mock

(B)

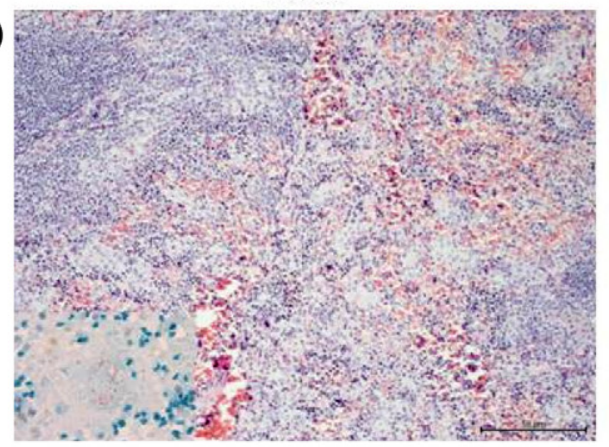

mpt64

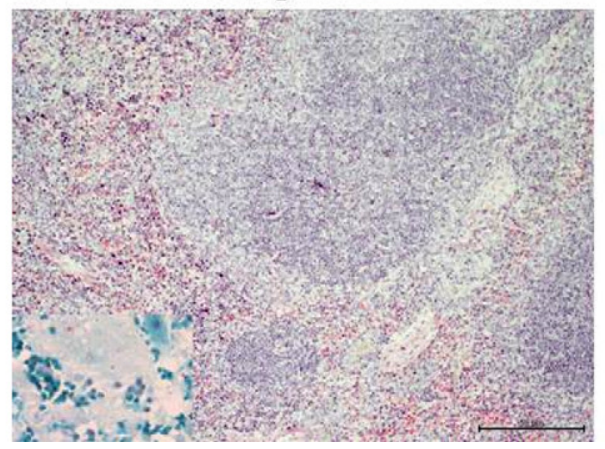

$\operatorname{leu} D$

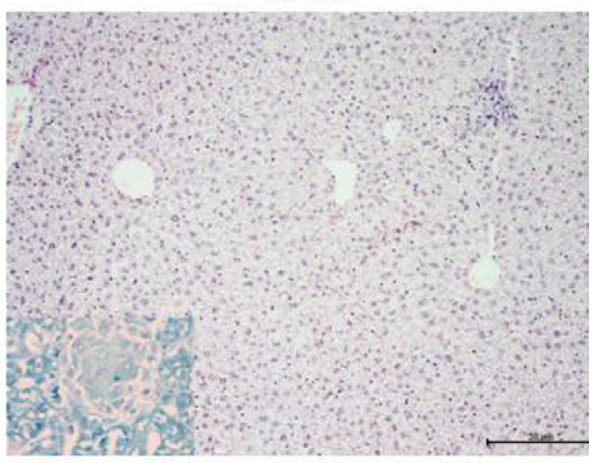

$\sec A 2$

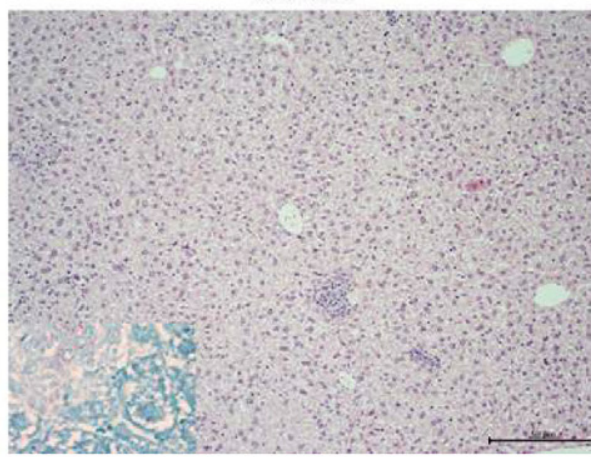

leuD

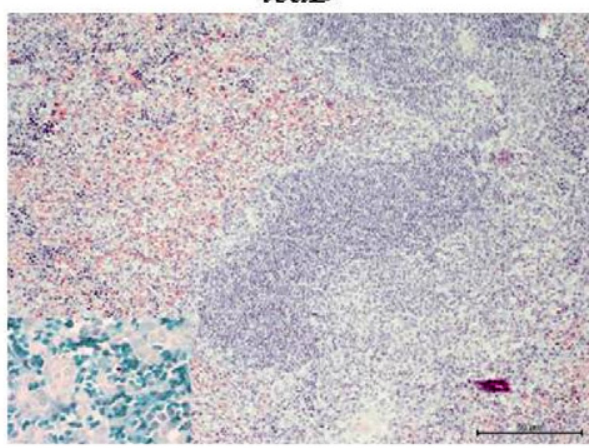

$\sec A 2$

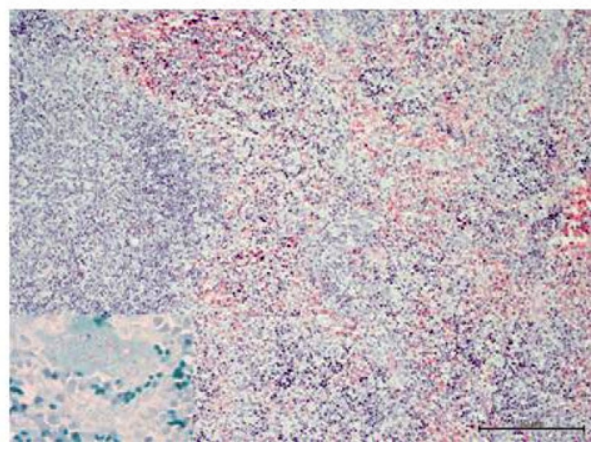

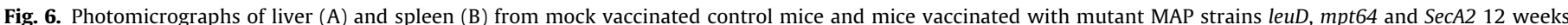

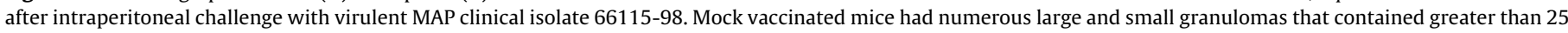

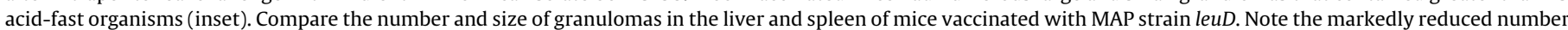

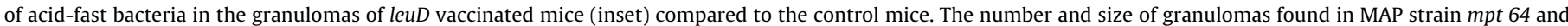
$\sec _{2}$ vaccinated mice are intermediate between the control mice and the leu $D$ vaccinated mice.

percentage of $\mathrm{CD} 8+\mathrm{T}$ cells than the control group; surprisingly, the leuD-vaccinated group splenocyte cultures had a lower proportion of $\mathrm{CD} 8+\mathrm{T}$ cells than the control group at week 12.
Immunization with mutants induced protective immunity against MAP challenge, as evidenced by more IFN- $\gamma$ secretion and a higher percentage of $C D 4+T$ cells compared to the mock vaccinated controls. The proportion of $\mathrm{CD} 8+\mathrm{T}$ cells in the leuD-vaccinated 
pg/ml

(A)

\section{pg/mi}

(B)
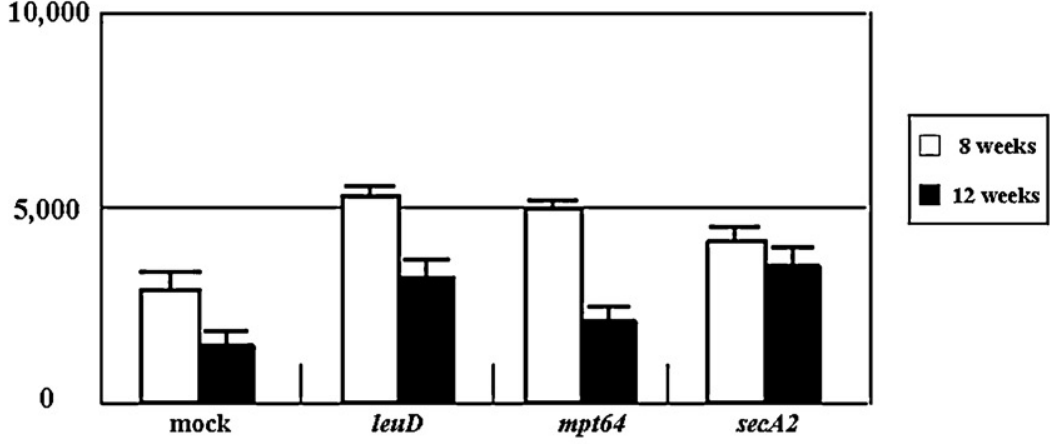

8 weeks

mock
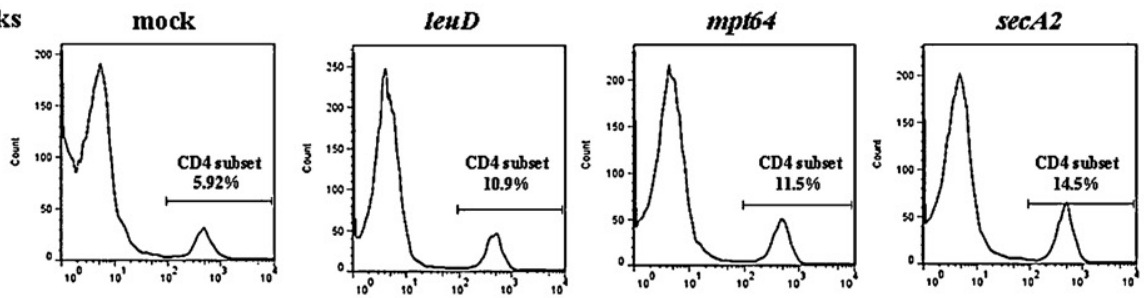

12 weeks
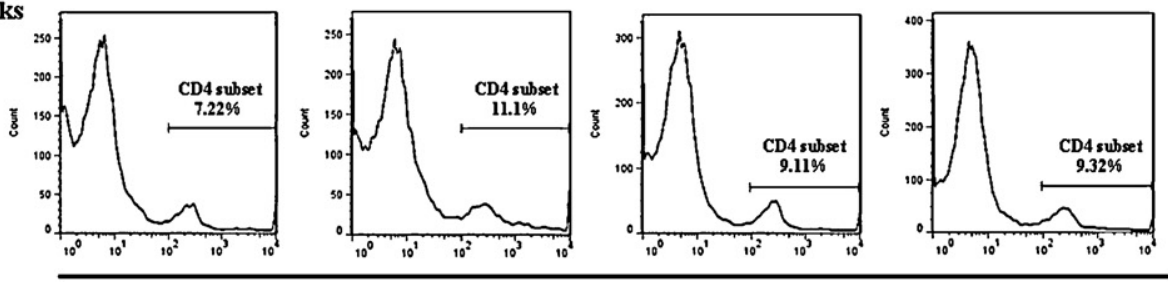

(C)

CD4
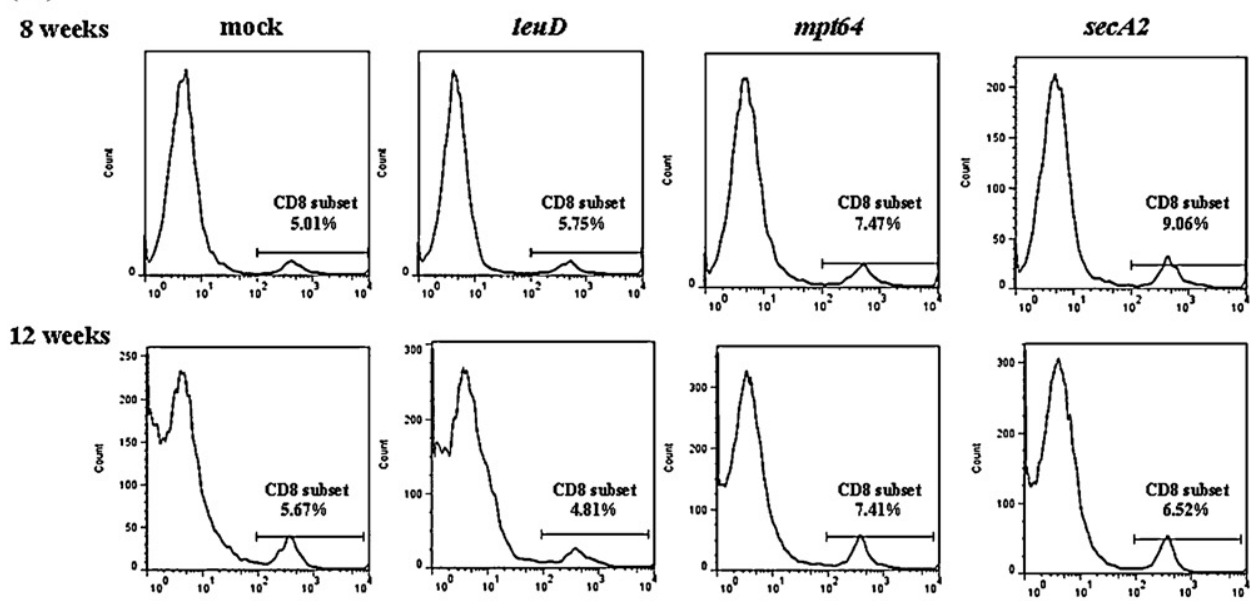

CD8

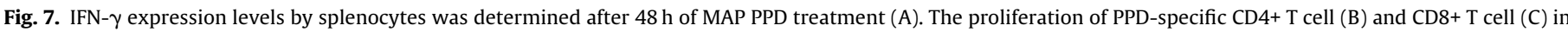
splenocytes was examined by staining with PE-antiCD4 and PE-antiCD8 antibodies.

group may be linked to the lower number of acid-fast bacilli. Nearly no acid-fast bacilli could be detected in the leuD-vaccinated group at week 12 (Fig. 5D), suggesting that fewer CD8+ T cell numbers were required compared to the control group that still contained acid-fast bacilli in splenic tissues.

\section{Discussion}

The development of an effective vaccine to control of JD remains one of the most challenging issues in animal health related to this disease. An improved and cost-effective vaccine against paratuberculosis is urgently required for the control of Johne's disease.
Advances in MAP genomics and molecular genetics provide an integrated rational approach to solve this problem. In this context, the search for new vaccine candidates is most effective if combined with novel approaches to develop a vaccine based on knowledge of the pathogenesis of mycobacterial infections such as M. tuberculosis or other intracellular pathogens. Since live attenuated vaccines can induce protective immunity against bovine and human tuberculosis in animal models, it is anticipated that a live vaccine against MAP will control JD more effectively. Targeting specific genes responsible for MAP survival or virulence offer attractive targets for development of live attenuated MAP vaccine candidates. As a key step to achieve this goal, we targeted three MAP genes 
(leuD, mpt64, and secA2) and successfully generated three different MAP mutants in which three wild-type genes were replaced respectively with a copy containing a defined deletion created by allelic exchange. These genes are linked to auxotrophy or virulence of MtB [14,16,18-20]. Moreover, the construction of MAP mutants could provide more detail about the nature of the pathogenicity and potential protective effect of those strains. Although the typical features of MAP infection in cattle (e.g., diarrhea, severe intestinal lesions) are not observed in mice, the murine model facilitates JD vaccine trials by allowing measurement of critical immune response parameters, MAP burden and inflammation level in the liver and spleen. We demonstrated that the leuD mutant was attenuated in $\mathrm{C} 57 \mathrm{BL} / 6$ mice and all three mutants provided better protection against MAP challenge in bacterial clearance; the leuD mutant was the only strain that could simultaneously reduce inflammation levels and acid-fast bacilli burden. We also evaluated the nature of the immune response elicited by these mutants. Data show that the leuD mutant elicited the highest IFN- $\gamma$ level, indicating the generation of T-cell immunity or cytotoxic CD8+ T cell responses, which are considered essential against intracellular pathogens.

Since using macrophages as a screening tool to examine the virulence of MAP mutants has been previously reported [12,27], we employed a similar strategy in this study using J774A.1 cells. The cells infected with mutants all expressed lower IL6 levels than the cells infected with $\mathrm{K}-10$; leuD- and secA2-infected cells expressed greater levels of IL10 than K-10-infected cells. Another pro-inflammatory cytokine, TNF- $\alpha$, had a similar expression pattern to IL6 and IL12b in J774A.1 cells in response to MAP infection (data not shown). It was reported some Mtb mutants down-regulated pro-inflammatory cytokine expression in macrophages [28,29]; the varied cytokine expression levels in macrophages infected with mutant MAP strains may be a valuable screening tool.

The leuD mutation causes attenuation of other Mycobacterium species and can induce protective immunity $[16,17]$. In our study, data showed that leuD mutant-vaccinated mice could eliminate most MAP from the liver and spleen, consistent with the results of other studies [16,17]. The linkage of between bacterial metabolism and virulence has been established and several groups have reported that auxotrophic mutants of pathogenic bacteria such as MTB and Shigella flexneri are attenuated for growth in vitro within macrophages and in animals in vivo [14,16,30-34]. Although defective leucine synthesis has a huge impact on the virulence of MAP, the effects of the leuD gene deletion in the MAP transcriptome still needs to be determined. Further, understanding the metabolic changes in the leuD mutant may help in the development other attenuated vaccine candidates.

Reportedly, the secretory protein Mpt64 of MtB inhibits apoptosis of multinucleated giant cells (MGCs) and plays a role in virulence. In our study, we found that the mpt64 mutant was eliminated more quickly than wild-type $\mathrm{K}-10$, especially from the spleen. Besides, different to other two mutants, mpt64 induced lower IL10 expression in J774A.1 cells than wild type K-10. The lower IL10 expression in macrophages with mpt64 infection may contribute to apoptosis. Therefore, our results also support the conclusion that Mpt64 has an important role in disease progression of MAP and additional studies are warranted to understand the mechanism by which Mpt64 inhibits apoptosis of host MGCs. The secA2 mutant strain is also attenuated and is a live vaccine candidate against MTB [20,21]. Similarly, the MAP secA2 mutant was also attenuated in a murine model, although it showed higher virulence than the leuD mutant. The MTB multiple gene deletion mutant $\triangle l y s A$ panCD $\triangle$ secA2 is currently in clinical vaccine trials $[35,36]$. Since this mutant currently in trials is a tetra-knockout and ours are only single knockout mutants, the $\triangle$ lys $\triangle \mathrm{panCD} \triangle \mathrm{sec} A 2$ mutant may be more attenuated than ours. We have used Ziehl-Neelsen staining to examine the numbers of acid-fast bacilli in tissue and found that the mutant-vaccinated groups had obviously fewer acidfast bacilli as compared to the mock-vaccinated group.

We determined that $1 \times 10^{7} \mathrm{CFU}$ was the optimum number of leuD mutant bacteria to induce protective immunity (Fig. 4). Further, the leuD mutant was the most obviously attenuated and induced the best level of protection among the three mutants. Further studies of these mutants in goats or calves are necessary to determine their potential for use as a live vaccine.

\section{Acknowledgments}

This work was supported by the Biotechnology Research and Development Corporation (BRDC), a contract through a cooperative agreement between the NYS Department of Agriculture and Markets, the USDA-APHIS, the National Research Initiative (NRI) of the USDA Cooperative State Research, Education and Extension Service (2008-35204-04626), the Agriculture and Food Research Initiative (AFRI) of the USDA Cooperative State Research, Education and Extension Service (2009-65119-05993) and the Animal Formula Fund (NY-478455 and NY-478437). Maria A.S. Moreira was supported by a scholarship from the Coordenacao de Aperfeicoamento de Pessoal de Nivel Superior (CAPES), Brazil.

\section{References}

[1] Bannantine JP, Chang YF, Kpaur V, editors. Mycobacteirum avium subspecies paratuberculosis. Washington, DC: ASM press; 2011.

[2] Chiodini RJ, Van Kruiningen HJ, Merkal RS. Ruminant paratuberculosis (Johne's disease): the current status and future prospects. Cornell Vet 1984;74(July (3)):218-62.

[3] Stehman SM. Paratuberculosis in small ruminants, deer, and South American camelids. Vet Clin North Am Food Anim Pract 1996;12(July (2)):441-55.

[4] Ott SL, Wells SJ, Wagner BA. Herd-level economic losses associated with Johne's disease on US dairy operations. Prev Vet Med 1999;40(June (3-4)):179-92.

[5] Wells SJ, Ott SL, Seitzinger AH. Key health issues for dairy cattle-new and old. J Dairy Sci 1998;81(November (11)):3029-35.

[6] Li L, Bannantine JP, Zhang Q, Amonsin A, May BJ, Alt D, et al. The complete genome sequence of Mycobacterium avium subspecies paratuberculosis. Proc Natl Acad Sci USA 2005;102(August (35)):12344-9.

[7] Chen LH, Kathaperumal K, Huang CJ, McDonough SP, Stehman S, Akey B, et al. Immune responses in mice to Mycobacterium avium subsp. paratuberculosis following vaccination with a novel $74 \mathrm{~F}$ recombinant polyprotein. Vaccine 2008;26(February (9)):1253-62.

[8] Kathaperumal K, Kumanan V, McDonough S, Chen LH, Park SU, Moreira MA et al. Evaluation of immune responses and protective efficacy in a goat model following immunization with a coctail of recombinant antigens and a polyprotein of Mycobacterium avium subsp. paratuberculosis. Vaccine 2009;27(January (1)):123-35.

[9] Kathaperumal K, Park SU, McDonough S, Stehman S, Akey B, Huntley J, et al. Vaccination with recombinant Mycobacterium avium subsp. paratuberculosis proteins induces differential immune responses and protects calves against infection by oral challenge. Vaccine 2008;26(March (13)):1652-63.

[10] Park SU, Kathaperumal K, McDonough S, Akey B, Huntley J, Bannantine JP, et al Immunization with a DNA vaccine cocktail induces a Th1 response and protects mice against Mycobacterium avium subsp. paratuberculosis challenge. Vaccine 2008;26(August (34)):4329-37.

[11] Shin SJ, Chang CF, Chang CD, McDonough SP, Thompson B, Yoo HS, et al. In vitro cellular immune responses to recombinant antigens of Mycobacterium avium subsp. paratuberculosis. Infect Immun 2005;73(August (8)):5074-85.

[12] Scandurra GM, de Lisle GW, Cavaignac SM, Young M, Kawakami RP, Collins DM. Assessment of live candidate vaccines for paratuberculosis in animal models and macrophages. Infect Immun 2010;78(March (3)):1383-9.

[13] Park KT, Allen AJ, Bannantine JP, Seo KS, Hamilton MJ, Abdellrazeq GS, et al. Evaluation of two mutants of Mycobacterium avium subsp. paratuberculosis as candidates for a live attenuated vaccine for Johne's disease. Vaccine 2011;29(June (29-30)):4709-19.

[14] Bange FC, Brown AM, Jacobs Jr WR. Leucine auxotrophy restricts growth of Mycobacterium bovis BCG in macrophages. Infect Immun 1996;64(May (5)):1794-9.

[15] McAdam RA, Weisbrod TR, Martin J, Scuderi JD, Brown AM, Cirillo JD, et al In vivo growth characteristics of leucine and methionine auxotrophic mutants of Mycobacterium bovis BCG generated by transposon mutagenesis. Infect Immun 1995;63(March (3)):1004-12.

[16] Hondalus MK, Bardarov S, Russell R, Chan J, Jacobs Jr WR, Bloom BR. Attenuation of and protection induced by a leucine auxotroph of Mycobacterium tuberculosis. Infect Immun 2000;68(May (5)):2888-98. 
[17] Khare S, Hondalus MK, Nunes J, Bloom BR, Garry Adams L. Mycobacterium bovis DeltaleuD auxotroph-induced protective immunity against tissue colonization, burden and distribution in cattle intranasally challenged with Mycobacterium bovis Ravenel S. Vaccine 2007;25(February (10)):1743-55.

[18] Mustafa T, Wiker HG, Morkve O, Sviland L. Reduced apoptosis and increased inflammatory cytokines in granulomas caused by tuberculous compared to non-tuberculous mycobacteria: role of MPT64 antigen in apoptosis and immune response. Clin Exp Immunol 2007;150(October (1)):105-13.

[19] Mustafa T, Wiker HG, Morkve O, Sviland L. Differential expression of mycobacterial antigen MPT64, apoptosis and inflammatory markers in multinucleated giant cells and epithelioid cells in granulomas caused by Mycobacterium tuberculosis. Virchows Arch 2008;452(April (4)):449-56.

[20] Braunstein M, Espinosa BJ, Chan J, Belisle JT, Jacobs Jr WR. SecA2 functions in the secretion of superoxide dismutase A and in the virulence of Mycobacterium tuberculosis. Mol Microbiol 2003;48(April (2)):453-64.

[21] Hinchey J, Lee S, Jeon BY, Basaraba RJ, Venkataswamy MM, Chen B, et al. Enhanced priming of adaptive immunity by a proapoptotic mutant of Mycobacterium tuberculosis. J Clin Invest 2007;117(August (8)):2279-88.

[22] Bardarov S, Bardarov Jr S, Pavelka Jr MS, Sambandamurthy V, Larsen M, Tufariello J, et al. Specialized transduction: an efficient method for generating marked and unmarked targeted gene disruptions in Mycobacterium tuberculosis, M. bovis BCG and M. smegmatis. Microbiology 2002;148(October (Pt 10)):3007-17.

[23] Braunstein M, Bardarov SS, Jacobs Jr WR. Genetic methods for deciphering virulence determinants of Mycobacterium tuberculosis. Methods Enzymol 2002;358:67-99.

[24] Park KT, Dahl JL, Bannantine JP, Barletta RG, Ahn J, Allen AJ, et al. Demonstration of allelic exchange in the slow-growing bacterium Mycobacterium avium subsp. paratuberculosis, and generation of mutants with deletions at the pknG, relA, and lsr2 loci. Appl Environ Microbiol 2008;74(March (6)):1687-95.

[25] Wu CW, Schmoller SK, Shin SJ, Talaat AM. Defining the stressome of Mycobacterium avium subsp. paratuberculosis in vitro and in naturally infected cows. J Bacteriol 2007;189(November (21)):7877-86.

[26] Abomoelak B, Hoye EA, Chi J, Marcus SA, Laval F, Bannantine JP, et al. mosR, a novel transcriptional regulator of hypoxia and virulence in Mycobacterium tuberculosis. J Bacteriol 2009;191(October (19)):5941-52.

[27] Scandurra GM, Young M, de Lisle GW, Collins DM. A bovine macrophage screening system for identifying attenuated transposon mutants of Mycobacterium avium subsp. paratuberculosis with vaccine potential. J Microbiol Methods 2009;77(April (1)):58-62.

[28] Dasgupta A, Sureka K, Mitra D, Saha B, Sanyal S, Das AK, et al. An oligopeptide transporter of Mycobacterium tuberculosis regulates cytokine release and apoptosis of infected macrophages. PLoS One 2010;5(8):e12225.

[29] Marjanovic O, Miyata T, Goodridge A, Kendall LV, Riley LW. Mce2 operon mutant strain of Mycobacterium tuberculosis is attenuated in C57BL/6 mice. Tuberculosis 2010;90(January (1)):50-6.

[30] Gordhan BG, Smith DA, Alderton H, McAdam RA, Bancroft GJ, Mizrahi V. Construction and phenotypic characterization of an auxotrophic mutant of Mycobacterium tuberculosis defective in L-arginine biosynthesis. Infect Immun 2002;70(June (6)):3080-4.

[31] Karnell A, Stocker BA, Katakura S, Reinholt FP, Lindberg AA. Live oral auxotrophic Shigella flexneri SFL124 vaccine with a deleted aroD gene: characterization and monkey protection studies. Vaccine 1992;10(6):389-94.

[32] Cersini A, Salvia AM, Bernardini ML. Intracellular multiplication and virulence of Shigella flexneri auxotrophic mutants. Infect Immun 1998;66(February (2)):549-57.

[33] Dick T, Manjunatha U, Kappes B, Gengenbacher M. Vitamin B6 biosynthesis is essential for survival and virulence of Mycobacterium tuberculosis. Mol Microbiol 2010;78(November (4)):980-8.

[34] Noriega FR, Losonsky G, Lauderbaugh C, Liao FM, Wang JY, Levine MM. Engineered deltaguaB-A deltavirG Shigella flexneri 2a strain CVD 1205: construction, safety, immunogenicity, and potential efficacy as a mucosal vaccine. Infect Immun 1996;64(August (8)):3055-61.

[35] Larsen MH, Biermann K, Chen B, Hsu T, Sambandamurthy VK, Lackner AA, et al. Efficacy and safety of live attenuated persistent and rapidly cleared Mycobacterium tuberculosis vaccine candidates in non-human primates. Vaccine 2009;27(July (34)):4709-17.

[36] Parida SK, Kaufmann SH. Novel tuberculosis vaccines on the horizon. Curr Opin Immunol 2010;22(June (3)):374-84.

[37] Shin SJ, Wu CW, Steinberg H, Talaat AM. Identification of novel virulence determinants in Mycobacterium paratuberculosis by screening a library of insertional mutants. Infect Immun 2006;74(July (7)):3825-33.

[38] Tanaka S, Sato M, Taniguchi T, Yokomizo Y. Histopathological and morphometrical comparison of granulomatous lesions in BALB/c and $\mathrm{C} 3 \mathrm{H} / \mathrm{HeJ}$ mice inoculated with Mycobacterium paratuberculosis. J Comp Pathol 1994;110(May (4)):381-8. 